\title{
Synthesis of C-15 Vindoline Analogues by Palladium-Catalyzed Cross-Coupling Reactions
}

\author{
Peter D. Johnson, Jeong-Hun Sohn, and Viresh H. Rawal \\ Department of Chemistry, University of Chicago, 5735 South Ellis Ave, Chicago, IL 60637, USA, \\ vrawal@uchicago.edu
}

\begin{abstract}
Described are general protocols for the rapid construction of various C-15-substituted analogs of vindoline using palladium-catalyzed cross-coupling reactions. The required bromo- and iodovindolines were prepared in high yield by the reaction of vindoline with $N$-bromosuccinimide or $N$-iodosuccinimide, respectively. The study not only led to the synthesis a number of structurally novel vindoline analogues but also opens the door to new strategies for the synthesis of vinblastine, vincristine, and related anticancer agents. Also described is the conversion of ent-tabersonine to ent-vindoline.
\end{abstract}

\section{INTRODUCTION}

Vinblastine (1) and vincristine (2) are two bisindole alkaloid natural products isolated from the Madagascar periwinkle, Catharanthus roseus G. Don (Figure 1). ${ }^{1}$ Both possess considerable antimitotic activity and thus have found use in treatment for various carcinomas, particularly childhood leukemia and Hodgkin's disease. ${ }^{2}$ The low natural availability and cytotoxic properties of these molecules have meant that considerable synthetic efforts have been expended to find efficacious analogues. In the forty years since the isolation of vinblastine, two such compounds, vindesine $\left(\mathbf{3} \text {, Eldesine }{ }^{\circledR} \text {, Lilly }\right)^{3}$ and vinorelbine $\left(\mathbf{4}\right.$, Navelbine ${ }^{\circledR}$, RerreFabre $)^{4}$ have found use in clinical treatment. A third, vinflunine $\left(\mathbf{5}\right.$, Javlor ${ }^{\circledR}$, Pierre-Fabre/ Bristol-Myers-Squibb), is currently in phase III clinical trials. ${ }^{5}$ The suggestion that these latter two compounds have similar, but different, modes of action to the natural compounds is encouraging for the prospect of further analogues to tackle cross-resistance.

In addition, there have been a number of efforts to synthesize vinblastine, both de novo and semi-synthetically from the much more naturally abundant vindoline and catharanthine by connection between C-15 at the former and C-18' at the latter. ${ }^{6}$ The coupling of these compounds has been accomplished several times and inevitably takes advantage of the nucleophilicity of vindoline at C-15.7 Recent efforts by Fahy have also made use of this reactivity to elaborate the vindoline skeleton by addition to glycolates. ${ }^{8}$ Our interest in the total synthesis of vinblastine drew our attention to the possibility of installing a halogen at C-15 of vindoline, which would allow for further elaboration at this position by utilizing the broad spectrum of cross-coupling reactions. ${ }^{9}$ These reactions are typically performed under mild conditions and provide a high degree of functional group tolerance. The implementation of this chemistry would allow introduction of novel substituents at $\mathrm{C}-15$, in addition to providing a versatile scaffold from which further synthetic elaborations could provide a new synthesis of vinblastine, vincristine, and related compounds. 


\section{RESULTS AND DISCUSSION}

Initial concerns about the electron-rich nature of the aryl ring, which slows down oxidative addition of Pd, prompted us to first investigate the feasibility of cross-coupling of such systems using a model compound. Thus a substituted carbazole containing the essential features of 15bromovindoline was first synthesized to serve as a platform for the development of optimum protocols for the cross-coupling reactions.

\section{A. Cross-Couplings of Model Compound}

The required model compound (11) was synthesized by a five-step sequence as shown in Scheme 1. Boc-hydrazine 6, a single regioisomer, was prepared in 76 to $83 \%$ yield following the known procedure. ${ }^{10}$ Treatment of this hydrazine with tosic acid and cyclohexanone in refluxing ethanol promoted in situ removal of the carbamate followed by the Fischer-Indole reaction. ${ }^{11}$ Two regioisomeric indoles were formed, due to the substitution pattern of the hydrazine, and these were separated by column chromatography to give pure indoles $7^{12}$ and $8^{13}$ in $41-43 \%$ and $16-21 \%$ yields, respectively. Indole 7 was reduced using $\mathrm{NaBH}_{3} \mathrm{CN}$ in the presence of $\mathrm{AcOH}$ to give $\mathbf{9}$ as a single diastereomer, which was protected directly as the pivalate (10) in good yield. Early exploration of the bromination of this system had shown that attenuation of the reactivity of the nitrogen lone pair was necessary to provide highly selective halogenation para to the amine, without competing dihalogenation. The desired bromination was achieved by simple treatment of the aniline with $\mathrm{NBS}$ in $\mathrm{MeCN}$ at room temperature to afford $\mathbf{1 1}$ in $86 \%$ yield. (Scheme 1)

Compound $\mathbf{1 1}$ was evaluated as a partner in various palladium catalyzed cross-coupling processes. Among these, the Suzuki reaction is arguably the most robust, as was investigated first. The Suzuki coupling of $\mathbf{1 1}$ and phenyl boronic acid proceeded smoothly under standard conditions to give the expected biaryl (12) in $68 \%$ yield (Scheme 2). We next examined the Heck reaction of $\mathbf{1 1}$ with a number of coupling partners. Considerable effort was put into optimizing the reaction conditions for this coupling, since such a reaction was expected to prove useful in other endeavors, such as the synthesis of vinblastine and analogs. Table 1 shows that the various conditions employed in the Heck coupling of $\mathbf{1 1}$ and methyl acrylate. It is clear that although the Heck reactions worked well the yields, even under optimized conditions, barely rivaled those of the Suzuki reaction. Best results were obtained using either $N, N$ dimethylformamide (DMF) or $N, N$-dimethylacetamide (DMA) as solvents and a large excess of a tertiary amine base. The yields were lower when the base was employed in stoichiometric amounts (entry 1 vs 4 and entry 2 vs 5). In most cases, the recovered starting material was contaminated with varying amounts of the corresponding dehalogenated compound. As reported in the literature, ${ }^{14}$ the use of 1 equivalent of $\mathrm{MeNCy}_{2}$ as the base reduced the extent of dehalogenation, but at the price of a lower isolated yield (entry 6 ). Of the palladium catalysts examined, $\mathrm{PdCl}_{2}\left[\mathrm{P}(o \text {-tol })_{3}\right]_{2}$ gave the best results in terms of turnover and yield. The optimized Heck protocol also allowed the coupling of bromide 11 with methyl vinyl ketone (entry 11), methyl cinnamate (entry 12), and dimethyl maleate (entry 13).

The coupling reactions of bromide $\mathbf{1 1}$ with ester enolates were also investigated. ${ }^{15}$ Such reactions are of particular interest because of their direct applicability to the synthesis of vinblastine and analogs. Even from this brief study (Table 2) it is clear that a variety of enolates can participate in the arylation. Of particular interest is the result shown in entry 2, since it demonstrates the coupling with an arylacetic ester, as would be required for the synthesis of vinblastine. 


\section{B. Cross-Coupling with Vindoline}

Having confirmed the feasibility of various cross-coupling methods on model compound $\mathbf{1 1}$, we turned our attention to the cross-coupling reactions of vindoline. In previous studies from this laboratory, we had described the gram-scale enantioselective synthesis of tabersonine and 16-methoxytabersonine. ${ }^{16}$ For the initial coupling studies, we converted synthetic 16 methoxytabersonine, which had been prepared in the enantiomeric form, to ent-vindoline through a sequence of three synthetic operations, following known procedures (Scheme 3). 17 Since the synthetic vindoline was precious and in the unnatural series, it was decided that all further transformations be carried out on natural vindoline. The conversion of vindoline to 15-bromovindoline (20) proved uneventful, since the conditions for bromination of the model system translated directly, allowing the formation of $\mathbf{2 0}$ in nearly quantitative yield. (Scheme 4) The corresponding 15 -iodovindoline (33, vide infra) was prepared similarly, in $97 \%$ yield, using NIS in MeCN.

B1. Suzuki Couplings-The conditions identified as effective for the Suzuki coupling of model compound $\mathbf{1 1}$ were utilized for the corresponding cross-couplings of bromovindoline with a broad range of boronic acids (Table 3). Aryl boronic acids, irrespective of their electronic nature, afforded biaryl products (21-26) in good yields. Particularly encouraging is the ability to use heteroaryl boronic acids, which allow access to a broad range of arylated vindoline analogs. The strategic introduction of functionality on these partners, which mimic the 'upper' portion of vinblastine, may allow the identification of new bioactive analogues of this important drug. Whereas aryl boronic acids reacted smoothly under the original conditions, vinyl boronic acids were less effective coupling partners, giving the products in moderate to low yields (entries 7 and 11). A ligand screen revealed that the commercially available X-PHOS ligand was highly effective at promoting this coupling. ${ }^{18}$ The use of X-PHOS not only allowed couplings with vinyl boronic acids (entries 10 and 12) but also an alkyl boronic acid (entry 13). Thus compounds $\mathbf{2 7}$ and $\mathbf{2 8}$ were formed in $\mathbf{7 5 \%}$ and $67 \%$ yields, respectively, and compound 29 was obtained in $52 \%$ yield. Of particular interest is entry 14, which shows the conversion of bromovindoline to the corresponding pinacol boronate. Ready access to this boronate has implications on the scope of Suzuki cross-couplings for the preparation of vindoline analogs. At the present time, the relative scarcity of commercially available boronic acids is perhaps the biggest limitation of the Suzuki reaction. With the availability of vindoline boronate, it should be possible to use the vast array of commercially available aryl and vinyl halides and prepare innumerable analogs of vindoline.

B2. Heck Couplings-Bromovindoline (20) is also an effective substrate for the Heck reaction. The reaction of bromide $\mathbf{2 0}$ with various alkenes gave the expected coupled products in moderate yields (Table 4). DMF was found to be more effective as solvent than DMA in light of not only the yield but also the easier removal of solvent from product. Similar yields were obtained with 15 -iodovindoline $\mathbf{3 3}$, which was prepared in a manner analogous to bromide 20.

B3. Other Couplings-Although ester $\alpha$-arylation reactions with model compound $\mathbf{1 1}$ gave the desired products in good yields for three different esters (Table 2), the analogous reaction with the bromovindoline $\mathbf{2 0}$ proved unsuccessful. It is likely that the reaction is complicated by the presence of the unprotected hydroxyl as well as the methyl ester at C-3 and the acetate at C-4. No starting material could be isolated from the reaction, nor were any other products identified.

Given the versatility of palladium catalyzed cross-coupling reactions, the halovindolines could be further elaborated in many different ways. We have examined two such transformations, the Sonogashira and the carbonylation reactions. Initially, the Sonogashira coupling of 
phenylacetylene bromovindoline $\mathbf{2 0}$ was attempted, but gave the coupled product in low yield, even at elevated temperatures. This problem was easily circumvented with the use of 15iodovindoline 33 , which reacted smoothly at room temperature to give the disubstituted acetylene 34 in $67 \%$ yield. Iodovindoline was also a superior substrate for the carbonylation reaction. The reaction was carried out in methanol under an atmosphere of carbon monoxide using a catalytic amount of $\mathrm{Pd}(\mathrm{OAc})_{2}$ and afforded the $\mathrm{C}-15$ methyl ester (35) in good yield. The introduction of a carbonyl group at this position provides a useful handle for further elaboration, and an extra degree of freedom in the design of analogues of vinblastine.

\section{CONCLUSION}

We have established a number of protocols for the introductions of both aryl and aliphatic substituents at C-15 of vindoline by palladium-catalyzed cross-coupling, without the need for protection of the functionalized vindoline nucleus. The compounds thus formed represent a number of structurally novel vindoline analogues. In addition, this method should allow the introduction of more elaborate substituents, particularly achiral aromatic structures, which mimic the 'upper' portion of vinblastine and thus represent a new class of vinblastine analogues.

\section{EXPERIMENTAL SECTION}

\section{General Coupling Procedures}

Suzuki A: A test tube was charged with bromovindoline $\mathbf{2 0}$ or iodovindoline $\mathbf{3 3}$ (1 equiv.), $\mathrm{K}_{2} \mathrm{CO}_{3}(1.5$ eq) the arylboronic acid (2 equiv.) and a magnetic stir bar. DME and water (3:1, to $0.1 \mathrm{M}$ in halovindoline) were added and the test tube sealed with a septum. The stirred solution was purged of oxygen by 5 vacuum-argon cycles. $\mathrm{Pd}\left(\mathrm{PPh}_{3}\right)_{4}(10 \mathrm{~mol} \%)$ was added, the system resealed with septum and parafilm and again purged of oxygen. The mixture was heated to $90{ }^{\circ} \mathrm{C}$ until TLC (50\% acetone-hexane) indicated the absence of starting material (typically 2-4 h). The mixture was cooled, diluted with EtOAc and filtered through Celite, and concentrated. The crude product was purified by column chromatography, eluting with $25 \%$ acetone-hexane. General Heck A, Heck B, and Suzuki B coupling procedures, and experimental details are in the Supporting Information. By the Suzuki A procedure, bromovindoline $20(20 \mathrm{mg}, 0.04 \mathrm{mmol})$ and phenyl boronic acid gave the biaryl 21 (14.9 mg, 75\%) as a white solid: ${ }^{1} \mathrm{H}$ NMR $\left(500 \mathrm{MHz}, \mathrm{CDC1}_{3}\right) \delta 9.58(\mathrm{br} \mathrm{s}, 1 \mathrm{H}), 7.41(\mathrm{~m}, 2 \mathrm{H}), 7.36(\mathrm{~m}$, $2 \mathrm{H}), 7.26(\mathrm{~m}, 1 \mathrm{H}), 6.94(\mathrm{~s}, 1 \mathrm{H}), 6.17(\mathrm{~s}, 1 \mathrm{H}), 5.86(\mathrm{ddd}, J=10.0,5.0,1.5 \mathrm{~Hz}, 1 \mathrm{H}), 5.49(\mathrm{~s}$, $1 \mathrm{H}), 5.25(\mathrm{~d}, J=10.0 \mathrm{~Hz}, 1 \mathrm{H}), 3.81(\mathrm{~s}, 3 \mathrm{H}), 3.80(\mathrm{~s}, 3 \mathrm{H}), 3.78(\mathrm{~s}, 1 \mathrm{H}), 3.50(\mathrm{ddd}, J=16.0,5.0$, $1.0 \mathrm{~Hz}, 1 \mathrm{H}), 3.43(\mathrm{~m}, 1 \mathrm{H}), 2.82(\mathrm{br} \mathrm{d}, J=16.0 \mathrm{~Hz}, 1 \mathrm{H}), 2.74(\mathrm{~s}, 3 \mathrm{H}), 2.72(\mathrm{~s}, 1 \mathrm{H}), 2.54-2.48$ (m, 1H), 2.37-2.34 (m, 2H), $2.08(\mathrm{~s}, 3 \mathrm{H}), 1.65(\mathrm{dq}, J=15.0,7.5 \mathrm{~Hz}, 1 \mathrm{H}), 1.20(\mathrm{dq}, J=14.5$, $7.5 \mathrm{~Hz}, 1 \mathrm{H}), 0.56(\mathrm{t}, J=7.5 \mathrm{~Hz}, 3 \mathrm{H}) ;{ }^{13} \mathrm{C} \mathrm{NMR}\left(125 \mathrm{MHz}, \mathrm{CDC1}_{3}\right) \delta 172.2,171.2,158.2$, 153.3, 139.3, 130.7, 129.7, 128.3, 126.6, 124.7, 124.5, 122.2, 94.0, 83.9, 79.9, 76.7, 67.3, 56.0, 53.3, 52.6, 52.3, 51.4, 44.3, 43.2, 38.9, 31.2, 21.4, 8.1; mp 107-112 ${ }^{\circ} \mathrm{C}$; IR (film) 1742, 1245, 1039; MS calculated for $\mathrm{C}_{31} \mathrm{H}_{37} \mathrm{~N}_{2} \mathrm{O}_{6}\left(\mathrm{MH}^{+}\right)$533.2, found 533.1.

\section{Supplementary Material}

Refer to Web version on PubMed Central for supplementary material.

\section{Acknowledgements}

Generous financial support from the National Cancer Institute of the NIH (R01 CA101438) is gratefully acknowledged. 


\section{References}

1. (a) Noble RL, Beer CT, Cutts JH. Ann N Y Acad Sci 1958;76:882. [PubMed: 13627916] (b) Svoboda GH, Neuss N, Gorman M. J Am Pharm Assoc Sci Ed 1959;48:659.

2. For a review of the medicinal chemistry of vinblastine, see: Antitumor Bisindole Alkaloids from Catharanthus roseus (L.) BrossiASuffnessMThe AlkaloidsAcademic Press Inc.San Diego199037Chapters 3 and 4133204

3. (a) Barnett CJ, Cullinan GJ, Gerzon K, Hoying RC, Jones WE, Newlon WM, Poore GA, Robison RL, Sweeney MJ, Todd GC, Dyke RW, Nelson RL. J Med Chem 1978;21:88. [PubMed: 412968] (b) Gokbuget N, Hoelzer D. Leukaemia and Lymphoma 1997;26:497.

4. (a) Potier P. Seminars in Oncology 1989;16:2. [PubMed: 2540531] (b) Gregory RK, Smith IE. British Journal of Cancer 2000;82:1907. [PubMed: 10864196]

5. (a) Fahy J, Duflos A, Ribet JP, Jacquesy JC, Berrier C, Jouannetaud MP, Zunino F. J Am Chem Soc 1997;119:8576. (b) Hill BT. Curr Pharm Des 2001;7:1199. [PubMed: 11472262]

6. For a review on synthetic studies, see: Antitumor Bisindole Alkaloids from Catharanthus roseus (L.). (a)BrossiASuffnessMThe AlkaloidsAcademic Press Inc.San Diego199037Chapter 277131 (b) Mangeney P, Andriamialisoa RZ, Langlois N, Langlois Y, Potier P. J Am Chem Soc 1979;101:2243. (c) Kutney JP, Choi LSL, Nakano J, Tsukamoto H, McHugh M, Boulet CA. Heterocycles 1988;27:1845. (d) Kuehne ME, Matson PA, Bornmann WG. J Org Chem 1991;56:513. (e) Magnus P, Mendoza JS, Stamford A, Ladlow M, Willis P. J Am Chem Soc 1992;114:10232. (f) Yokoshima S, Ueda T, Kobayashi S, Ayato S, Kuboyama T, Tokuyama H, Fukuyama T. J Am Chem Soc 2002;124:2137. [PubMed: 11878966]

7. (a) Harley-Mason J, Atta-Ur-Rahman. Tetrahedron 1980;36:1057. (b) Kutney JP, Beck J, Bylsma F, Cretney WJ. J Am Chem Soc 1968;90:4504. [PubMed: 5666353] (c) Magnus P, Mendoza JS, Stamford A, Ladlow M, Willis P. J Am Chem Soc 1992;114:10232. (d) Langlois N, Gueritte F, Langlois Y, Potier P. J Am Chem Soc 1976;98:7017. [PubMed: 965661] (e) Vukovic J, Goodbody AE, Kutney JP, Misawa M. Tetrahedron 1988;44:325. (f) Misawa M, Endo T, Goodbody A, Vukovic J, Chappie C, Choi L, Kutney JP. Phytochemistry 1988;27:1355.Tabakovic T, Gunic E, Juranic I. J Org Chem 1997;62:947.

8. Fahy J, du Boullay VT, Bigg DCH. Bioorg Med Chem Lett 2002;12:505. [PubMed: 11814829]

9. During the preparation of this manuscript, a communication describing some similar transformations was published: Fekete M, Kalonits P, Novak L. Heterocycles 2005;65:165. This communication reports the slow nature of the Suzuki coupling of 15-bromovindoline, in contrast to our findings.

10. Wolter M, Klapars A, Buchwald SL. Org Lett 2001;3:3803. [PubMed: 11700143]

11. Lim Y-K, Cho C-G. Tetrahedron Lett 2004;45:1857.

12. Banwell MG, Kelly BD, Kokas OJ, Lupton DW. Org Lett 2003;5:2497. [PubMed: 12841764]

13. Kawase M, Miyake Y, Kikugawa Y. J Chem Soc Perkin Trans 1984;1:1401.

14. This base has been shown to be particularly effective in Heck couplings: Gurtler C, Buchwald SL. Chem Eur J 1999;5:3107.

15. (a) Moradi WA, Buchwald SL. J Am Chem Soc 2001;123:7996. [PubMed: 11506555] (b) Lee S, Beare NA, Hartwig JF. J Am Chem Soc 2001;123:8410. [PubMed: 11516296] (c) Jørgensen M, Lee S, Liu X, Wolkowski JP, Hartwig JF. J Am Chem Soc 2002;124:12557. [PubMed: 12381200] (d) Hama T, Liu X, Culkin DA, Hartwig JF. J Am Chem Soc 2003;125:11176. [PubMed: 16220921] (e) Liu X, Hartwig JF. J Am Chem Soc 2004;126:5182. [PubMed: 15099101]

16. Kozmin SA, Iwama T, Huang Y, Rawal VH. J Am Chem Soc 2002;124:4628. [PubMed: 11971711]

17. (a) Barton DHR, Hui RAHF, Ley SV, Williams DJ. J Chem Soc Perkin Trans 1982;1:1919. (b) Danieli B, Lesma G, Palmisano G, Riva R. J Chem Soc Chem Commun 1984:909. (c) Kobayashi S, Ueda T, Fukuyama T. Synlett 2000:883.

18. Strieter ER, Blackmond DG, Buchwald SL. J Am Chem Soc 2003;125:13978. [PubMed: 14611232] 


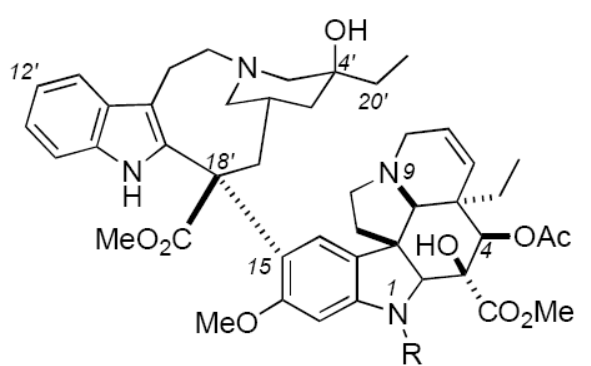

$\mathrm{R}=\mathrm{Me}$

vinblastine (1, VLB)

$\mathrm{R}=\mathrm{CHO}$ vincristine $(2, \mathrm{VCR})$

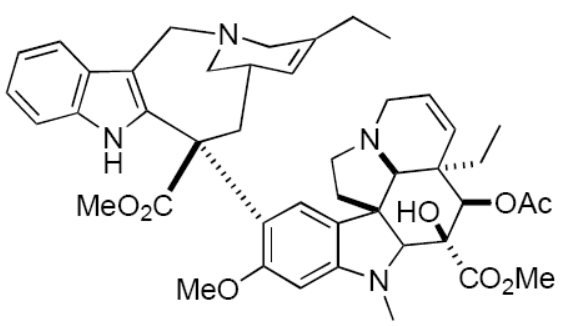

vinorelbine (4, VRLB)

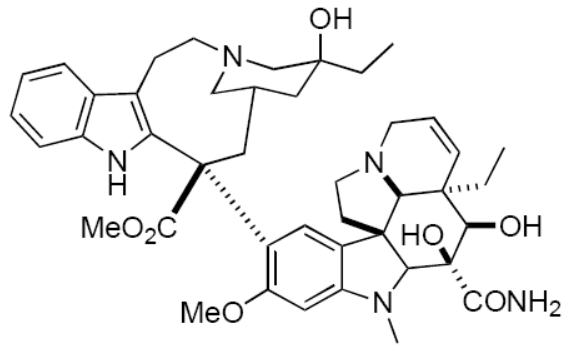

vindesine $(3, \mathrm{VDS})$

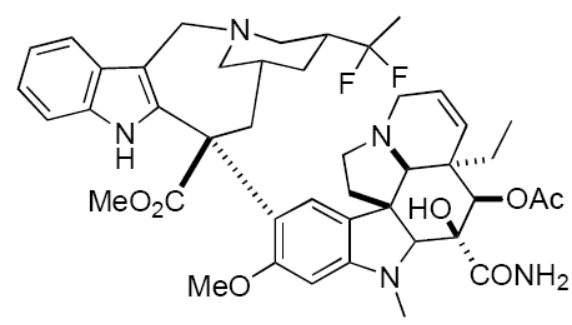

vinflunine $(5, V F L)$

Figure 1.

Clinically efficacious bisindole alkaloids and derivatives 


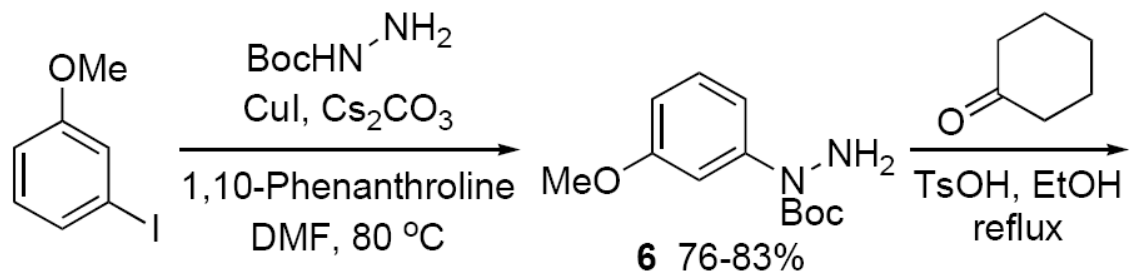<smiles>COc1ccc2c(c1)NC1CCCC[C@H]21</smiles>
$816-21 \%$

$741-43 \%$

$990-93 \%$

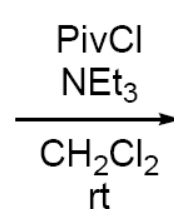<smiles>COc1ccc2c(c1)[C@H]1CCCC[C@H]1N2P</smiles>

$1060-69 \%$

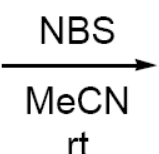

rt<smiles>COc1cc2c(cc1Br)[C@@H]1CCCC[C@H]1N2P</smiles>

$1186 \%$

Scheme 1.

Synthesis of model compound $\mathbf{1 1}$ 


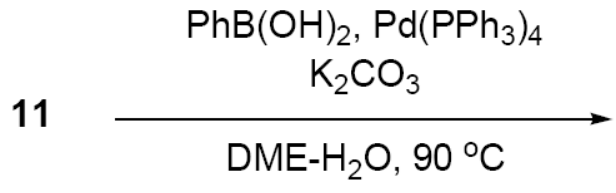

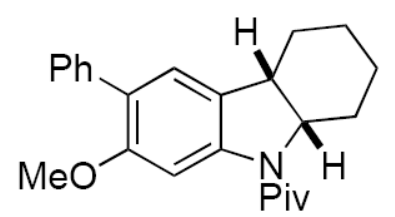

$1268 \%$

Scheme 2.

Suzuki reaction of $\mathbf{1 1}$ with phenyl boronic acid 


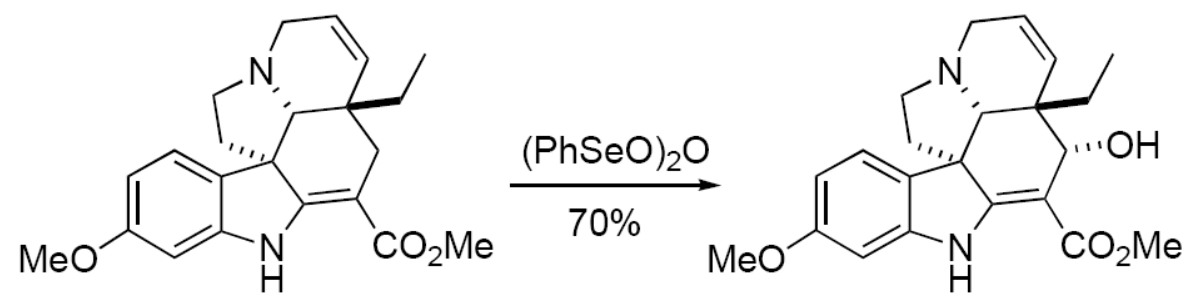

16-methoxytabersonine $\underset{\mathrm{m} \text {-CPBA, } \mathrm{NaHCO}_{3} ;}{\mathrm{HCHO}, \mathrm{NaBH}_{3} \mathrm{CN}} \downarrow 21 \%$

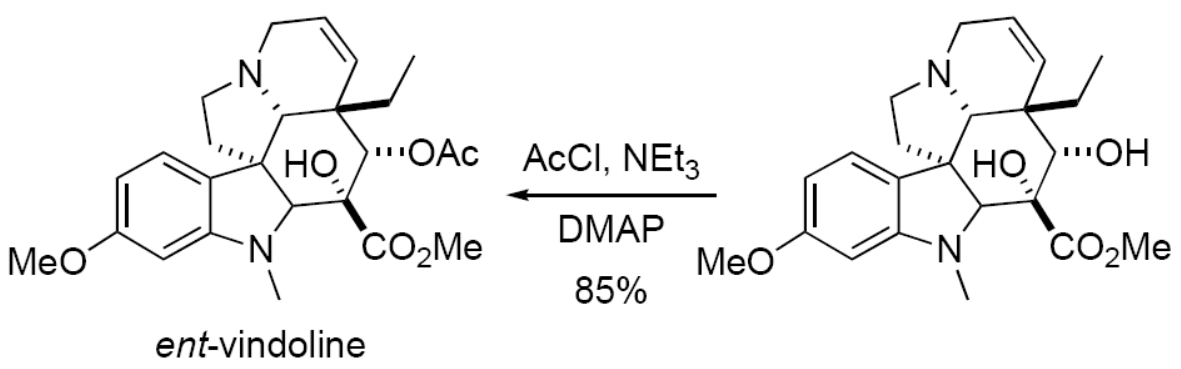

Scheme 3.

Conversion of ent-16-methoxytabersonine to ent-vindoline 


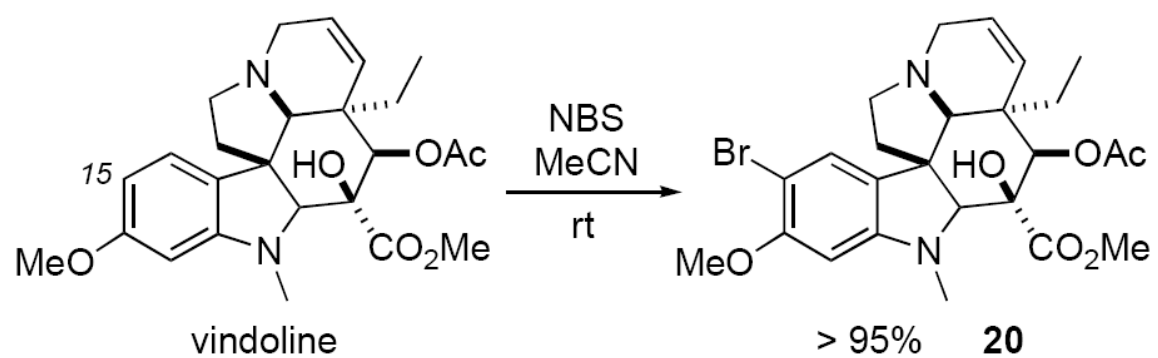

Scheme 4.

Bromination of vindoline with NBS 
Table 1

Heck couplings of aryl bromide $11^{a}$

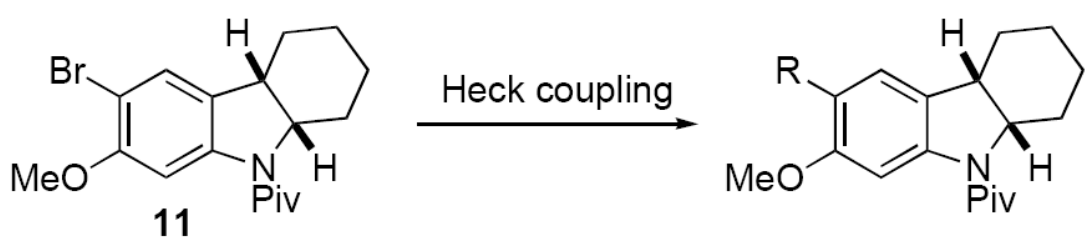

\begin{tabular}{|c|c|c|c|c|}
\hline entry & coupling partner & solvent & product; $\mathbf{R}$ & $\operatorname{yield}(\%)^{b}$ \\
\hline 1 & methyl acrylate & $\mathrm{DMF} \mathrm{NEt}_{3}(1: 1)$ & MeO & $57(57)$ \\
\hline 2 & methyl acrylate & DMF $n-\mathrm{Bu}_{3} \mathrm{~N}(1: 1)$ & 13 & $62(67)$ \\
\hline 3 & methyl acrylate & $\mathrm{DMF} \mathrm{MeNCy}_{2}(1: 1)$ & 13 & n.d. ${ }^{c}$ \\
\hline 4 & methyl acrylate & $\mathrm{DMF} \mathrm{NEt}_{3}$ (1 equiv.) & 13 & $8(11)^{d}$ \\
\hline 5 & methyl acrylate & DMF $n-\mathrm{Bu}_{3} \mathrm{~N}(1$ equiv. $)$ & 13 & $30(49)^{d}$ \\
\hline 6 & methyl acrylate & $\mathrm{DMF} \mathrm{MeNCy}_{2}(1$ equiv. $)$ & 13 & $43(76)^{d}$ \\
\hline 7 & methyl acrylate & $\operatorname{DMA~NEt}_{3}(1: 1)$ & 13 & $70(70)$ \\
\hline 8 & methyl acrylate & $\operatorname{DMSO~NEt}_{3}(1: 1)$ & 13 & 0 \\
\hline 9 & methyl acrylate & dioxane $\mathrm{NEt}_{3}(1: 1)$ & 13 & $37(37)$ \\
\hline 10 & methyl acrylate & $\operatorname{DMF~NEt}_{3}(1: 1)$ & 13 & $15(48)^{e}$ \\
\hline 11 & methyl vinyl ketone & $\mathrm{DMA} \mathrm{NEt}_{3}(1: 1)$ & & $49(96)$ \\
\hline 12 & methyl cinnamate & $\operatorname{DMANEt}_{3}(1: 1)$ & & $29(29)$ \\
\hline 13 & dimethyl maleate & DMA NEt $_{3}(1: 1)$ & & $69(69)$ \\
\hline
\end{tabular}

${ }^{a}$ Reactions were conducted using 5 equiv. of alkene, $25 \mathrm{~mol} \% \mathrm{PdCl}_{2}[\mathrm{P}(o$-tol $) 3] 2$ at $100{ }^{\circ} \mathrm{C}$ until reaction was judged complete by TLC.

$b_{\text {Isolated yield. Yields in parentheses are based on recovered starting material. }}$

${ }^{c}$ Product contaminated with amine.

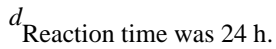

${ }^{e} \mathrm{Pd}(\mathrm{OAc}) 2[\mathrm{P}(o-\mathrm{tol}) 3] 2$ was used as catalyst. 
Ester $\alpha$-arylations using bromide 11

\section{Table 2}

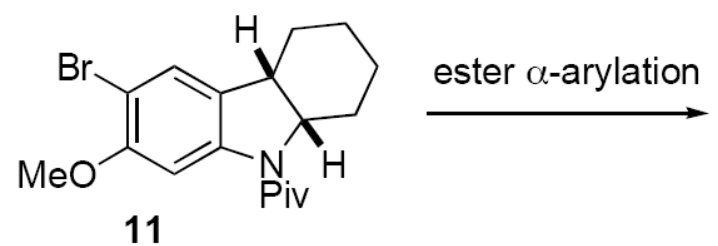<smiles>[R]c1cc2c(cc1OC)[C@H]1CCCC[C@H]1N2[NH2+]</smiles>

\begin{tabular}{|c|c|c|c|c|}
\hline entry & coupling partner & conditions & product; $\mathbf{R}$ & $\operatorname{yield}(\%)$ \\
\hline 1 & & $\begin{array}{c}\mathrm{Pd}_{2}(\mathrm{dba})_{3}, \mathrm{LiHMDS} \mathrm{L}^{*}, \mathrm{PhCH}_{3}, \\
\text { rt, } 24 \mathrm{~h}\end{array}$ & $\mathrm{BBuO}_{2} \mathrm{C} \bigcirc \mathrm{s}$ & 54 \\
\hline 2 & $\mathrm{Ph} \smile \mathrm{CO}_{2} \mathrm{Me}$ & $\begin{array}{c}\mathrm{Pd}_{2}(\mathrm{dba})_{3}, \mathrm{LiHMDS} \mathrm{L}^{*}, \mathrm{PhCH}_{3}, \\
50^{\circ} \mathrm{C}, 18 \mathrm{~h}\end{array}$ & $\mathrm{MeO}_{2} \mathrm{C}^{-}$ & 47 \\
\hline 3 & ОтMS & $\begin{array}{c}\mathrm{Pd}_{2}(\mathrm{dba})_{3}, \mathrm{P}^{\mathrm{f}} \mathrm{Bu}_{3}, \mathrm{ZnF}_{2} \mathrm{DMF}, 80 \\
{ }^{\circ} \mathrm{C}, 24 \mathrm{~h}\end{array}$ & ${ }_{\mathrm{MeO}_{2} \mathrm{C}} \mathrm{X}_{\xi} 19$ & 59 \\
\hline
\end{tabular}

${ }^{a}$ Product was obtained as a 7:1 mixture of diastereomers. 
Suzuki couplings of bromovindoline 20

\section{Table 3}

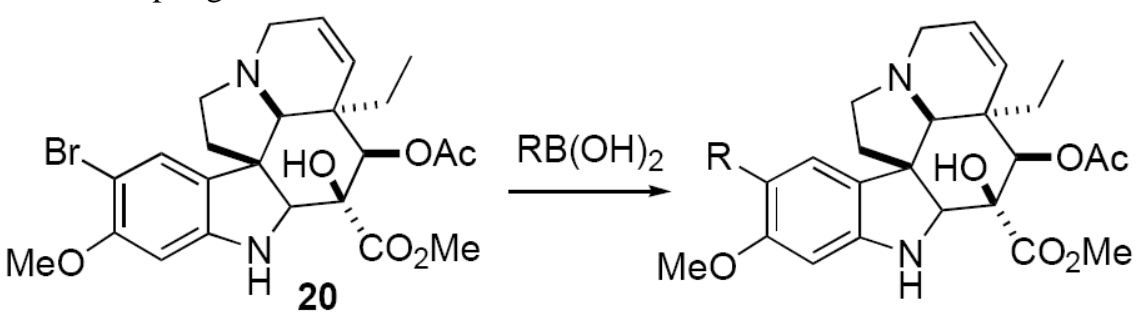

\begin{tabular}{|c|c|c|c|}
\hline entry & conditions $^{a}$ & product; $\mathbf{R}$ & $\operatorname{yield}(\%)$ \\
\hline 1 & $\mathrm{Pd}\left(\mathrm{PPh}_{3}\right)_{4}, \mathrm{~K}_{2} \mathrm{CO}_{3} \mathrm{DME}-\mathrm{H}_{2} \mathrm{O}, 1 \mathrm{~h}$ & 21 & 75 \\
\hline 2 & $\mathrm{Pd}\left(\mathrm{PPh}_{3}\right)_{4}, \mathrm{~K}_{2} \mathrm{CO}_{3}$ DME- $\mathrm{H}_{2} \mathrm{O}, 2 \mathrm{~h}$ & & 59 \\
\hline 3 & $\mathrm{Pd}\left(\mathrm{PPh}_{3}\right)_{4}, \mathrm{~K}_{2} \mathrm{CO}_{3} \mathrm{DME}-\mathrm{H}_{2} \mathrm{O}, 14 \mathrm{~h}$ & & 77 \\
\hline 4 & $\mathrm{Pd}\left(\mathrm{PPh}_{3}\right)_{4}, \mathrm{~K}_{2} \mathrm{CO}_{3} \mathrm{DME}-\mathrm{H}_{2} \mathrm{O}, 20 \mathrm{~h}$ & 24 & 38 \\
\hline 5 & $\mathrm{Pd}\left(\mathrm{PPh}_{3}\right)_{4}, \mathrm{~K}_{2} \mathrm{CO}_{3} \mathrm{DME}-\mathrm{H}_{2} \mathrm{O}, 23 \mathrm{~h}$ & & 35 \\
\hline 6 & $\mathrm{Pd}\left(\mathrm{PPh}_{3}\right)_{4}, \mathrm{~K}_{2} \mathrm{CO}_{3} \mathrm{DME}-\mathrm{H}_{2} \mathrm{O}, 19 \mathrm{~h}$ & 20 & 45 \\
\hline 7 & $\mathrm{Pd}\left(\mathrm{PPh}_{3}\right)_{4}, \mathrm{~K}_{2} \mathrm{CO}_{3}$ DME- $\mathrm{H}_{2} \mathrm{O}, 18 \mathrm{~h}$ & & 49 \\
\hline 8 & $\mathrm{Pd}(\mathrm{OAc})_{2}, \mathrm{~K}_{2} \mathrm{CO}_{3}, \mathrm{DPEphos} \mathrm{PhCH}_{3}, 16 \mathrm{~h}$ & & 0 \\
\hline 9 & $\begin{array}{l}\mathrm{Pd}(\mathrm{OAc})_{2}, \mathrm{~K}_{2} \mathrm{CO}_{3}, \mathrm{PhCH}_{3}, 16 \text { h 2-di-tert-butylphosphino } \\
\text { biphenyl }\end{array}$ & 27 & 10 \\
\hline 10 & $\mathrm{Pd}(\mathrm{OAc})_{2}, \mathrm{~K}_{2} \mathrm{CO}_{3}, \mathrm{X}-\mathrm{PHOS} \mathrm{PhCH}_{3}, 16 \mathrm{~h}$ & & 75 \\
\hline 11 & $\mathrm{Pd}\left(\mathrm{PPh}_{3}\right)_{4}, \mathrm{~K}_{2} \mathrm{CO}_{3} \mathrm{DME}-\mathrm{H}_{2} \mathrm{O}, 16 \mathrm{~h}$ & & 30 \\
\hline 12 & $\mathrm{Pd}(\mathrm{OAc})_{2}, \mathrm{~K}_{2} \mathrm{CO}_{3}, \mathrm{X}-\mathrm{PHOS} \mathrm{PhCH}_{3}, 18 \mathrm{~h}$ & $s^{5}$ & 67 \\
\hline 13 & $\mathrm{Pd}(\mathrm{OAc})_{2}, \mathrm{~K}_{2} \mathrm{CO}_{3}, \mathrm{X}-\mathrm{PHOS} \mathrm{PhCH}_{3}, 18 \mathrm{~h}$ & 29 & 52 \\
\hline $14^{b}$ & $\operatorname{Pd}(\mathrm{dppf}) \mathrm{Cl}_{2}, \mathrm{KOAc}, \mathrm{DMF}, 16 \mathrm{~h}$ & & 64 \\
\hline
\end{tabular}

\footnotetext{
${ }^{a}$ All reactions were run at $90^{\circ} \mathrm{C}$, with 2 equiv. of boronic acid.

$b_{\text {Iodovindoline } \mathbf{3 3} \text { was used. }}$
} 


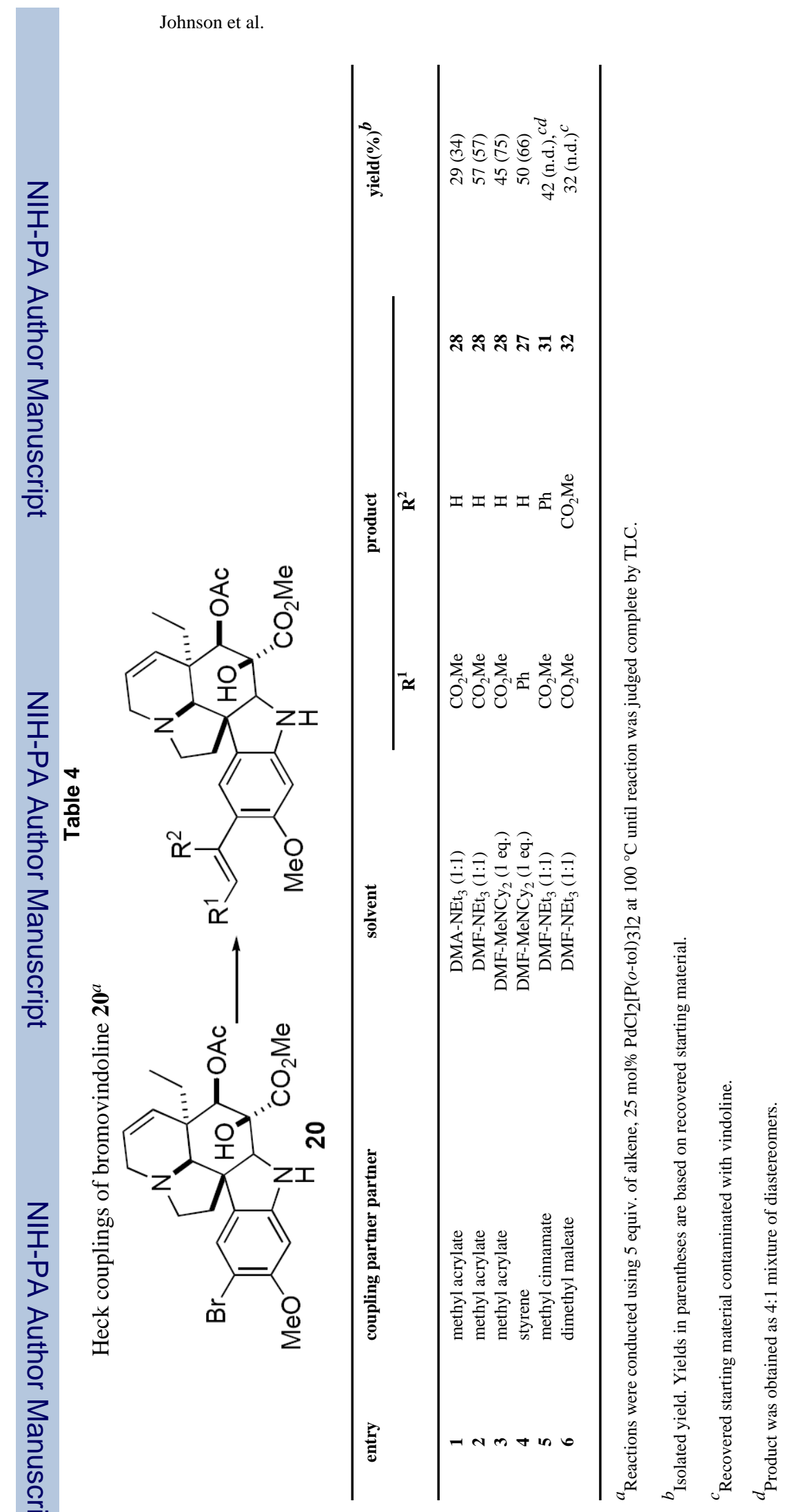

Page 14 
Table 5

Additional coupling reactions of iodovindoline $\mathbf{3 3}$

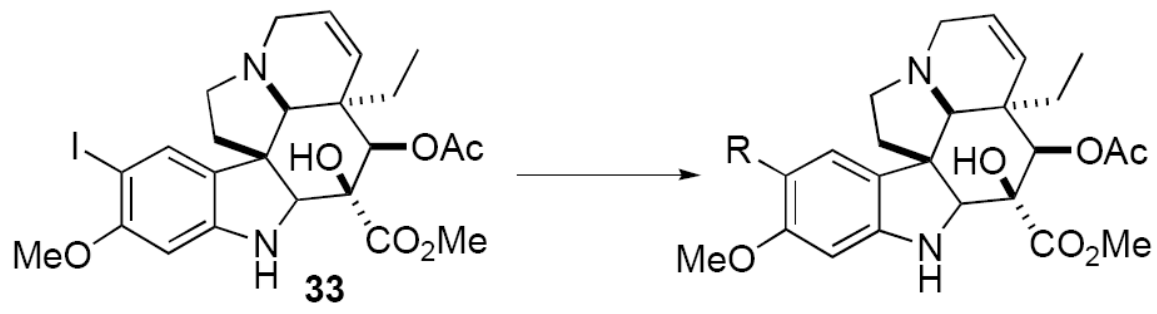

\begin{tabular}{clccc}
\hline entry & coupling partner & conditions & product; $\mathbf{R}$ & yield(\%) \\
\hline $\mathbf{1}$ & phenyl acetylene & $\mathrm{Pd}\left(\mathrm{PPh}_{3}\right)_{4}, \mathrm{Cul}, \mathrm{NEt}_{3} \mathrm{MeCN}, 18 \mathrm{~h}, 80^{\circ} \mathrm{C}$ & $\mathrm{Ph}=-\mathbf{3 4}$ & $18^{a}$ \\
$\mathbf{2}$ & phenyl acetylene & $\mathrm{Pd}\left(\mathrm{PPh}_{3}\right)_{4}, \mathrm{Cul}, \mathrm{NEt}{ }_{3} \mathrm{MeCN}, 18 \mathrm{~h}, \mathrm{rt}$ & $\mathrm{Ph}=-34$ & 67 \\
$\mathbf{3}$ & $\mathrm{CO} \mathrm{MeOH}$ & $\mathrm{Pd}(\mathrm{OAc})_{2}, \mathrm{NEt}_{3}, \mathrm{CO} \mathrm{MeOH}, 36 \mathrm{~h}, 65^{\circ} \mathrm{C}$ & $\mathrm{CO}_{2} \mathrm{Me} \mathbf{3 5}$ & 60 \\
\hline
\end{tabular}

${ }^{a}$ Bromovindoline was used. 